\title{
NADİR GÖRÜLEN SKROTAL LEZYON: SKROTAL HEMANJIOM OLGU SUNUMU
}

\author{
A Rare Scrotal Lesion: Scrotal Hemangioma
}

\section{Mustafa Koray KIRDAĞ ${ }^{1}$, Fatih BAL ${ }^{1}$, Devrim TUĞLU ${ }^{2}$}

${ }^{I}$ Kırlkkale Yüksek İhtisas Hastanesi Üroloji Kliniği, KIRIKKALE, TÜRKIYE

${ }^{2}$ Kırlkkale Üniversitesi Tip Fakültesi Hastanesi Üroloji A.D., KIRIKKALE, TÜRKIYY

\section{ÖZ}

ABSTRACT

Hemanjiomlar en sık görülen benign vasküler lezyonlardır. Kadınlarda erkeklere göre 3 kat daha fazla görülmektedir. $\mathrm{Bu}$ vasküler lezyonlar genellikle asemptomatik seyrederler ve rastlantısal olarak tespit edilirler. Hemanjiomlar farklı biyolojik davranışlar gösterirler. Hemanjiomların farklı tedavi yöntemleri mevcuttur. Yüzeyel hemanjiomlar, spontan regresyon olasılığından dolayı genellikle takip edilirler. Diğer hemanjiom türlerinde ise cerrahi ve cerrahi dışı tedavi yöntemleri (IFN-a, steroidler, sklerozan ajanlar, lazer) uygulanabilir. Skrotal hemanjiom ise skrotumun nadir görülen vasküler benign tümörüdür. Preoperatif değerlendirmede doppler ultrasonografi, bilgisayarlı tomografi ve manyetik rezonans gibi görüntüleme yöntemleri kullanılabilir. $\mathrm{Bu}$ yazıda, skrotal kitle nedeniyle operasyon yapılan 25 yaşında erkek hastada skrotal hemanjiom olgusu sunuldu.

Anahtar Kelimeler: Skrotal kitle, skrotal hemanjiom, nadir vasküler lezyon
Hemangiomas are the most frequently seen benign vascular lesions. They are encountered three times more common in females. These lesions are generally asymptomatic and are usually detected incidentally. Hemangiomas show different biological behaviors and there exist different treatment methods. Superficial hemangiomas are generally observed due to the possibility of spontaneous regression. Yet, other types of hemangiomas involve surgical and non-surgical (IFN-a, steroids, sclerosing agents, laser) treatment methods. Scrotal hemangioma, however, is a rarely seen benign vascular tumor of the scrotum. The preoperative evaluation may include imaging modalities such as doppler ultrasonography, computerized tomography and magnetic resonance imaging. This article presents the case of a scrotal hemangioma in a twenty-five years old patient who underwent surgery for a scrotal mass.

Keywords: Scrotal mass, scrotal hemangioma, rare vascular lesion 


\section{GİRIŞ}

Hemanjiomlar en s1k görülen benign vasküler lezyonlardır. Hemanjiomlar heterojen bir kliniğge sahip olup, büyüklüklerine, yerleşim yerlerine, yüzeysel veya derin oluşlarına ve hücre çoğalması açısından evrelerine göre farklı özellikler göstermektedirler (1). Histolojik olarak kapiller, kavernöz ve karışık olmak üzere alt gruplara ayrılırlar (2). Yüzeysel hemanjiomlar kırmızı renkte olup keskin sınırlı nodül veya plak şeklindedirler (3). Hemanjiomların bayanlarda görülme oranı erkeklerden 3 kat daha fazladır (4). Genellikle görüntüleme yöntemleri esnasında rastlantısal olarak tespit edilirler ve asemptomatik seyrederler (5). Hemanjiomlar çocukluk çağında sık görülmektedirler. Çocukluk çağında 0-1 yaş arası hemanjiom görülme oranı \%10'dur (6). Hemanjiomların tedavisi planlanırken lezyonun lokalizasyonu, patolojik türü, hastanın yaşı göz önünde bulundurulmalıdır. Tedavi yöntemi olarak takip, cerrahi ve cerrahi dışı yöntemler (IFN-a, steroidler, sklerozan ajanlar, lazer) kullanılabilir (7). Skrotal yerleşim hemanjiomlar için sık görülen lokalizasyon değildir. Literatürde yaklaşık elli skrotal hemanjiom vakası bildirilmiştir.

\section{OLGU}

25 yaşında erkek hasta sağ skrotumunda kitle nedeniyle polikliniğimize başvurdu. Yapılan fizik muayenesinde sağ skrotum üst kesimde yaklaşık $6 \times 3 \mathrm{~cm}$ boyutunda damarlanması yoğun olan kitle palpe edildi. Bilateral testisler mobil idi (Resim 1). Hastanın anamnezinde travma ve geçirilmiş cerrahi olmadığı tespit edildi. Hastanın çekilen skrotal doppler ultrasonografisinde sağ inguinal kanal distalinden başlayan skrotuma kadar uzanan $65 \times 30 \mathrm{~mm}$ boyutunda yoğun kanlanan, hemanjiom lehine görünüm tespit edildi. Hastanın rutin kanları ve koagülasyon profili normal idi. Hastanın tümör markırları negatif idi. Dokunun operasyon esnasında sağ inguinal kanal distal kısmından skrotuma kadar uzandığı ve spermatik kord üzerine yapışık olduğu görüldü.

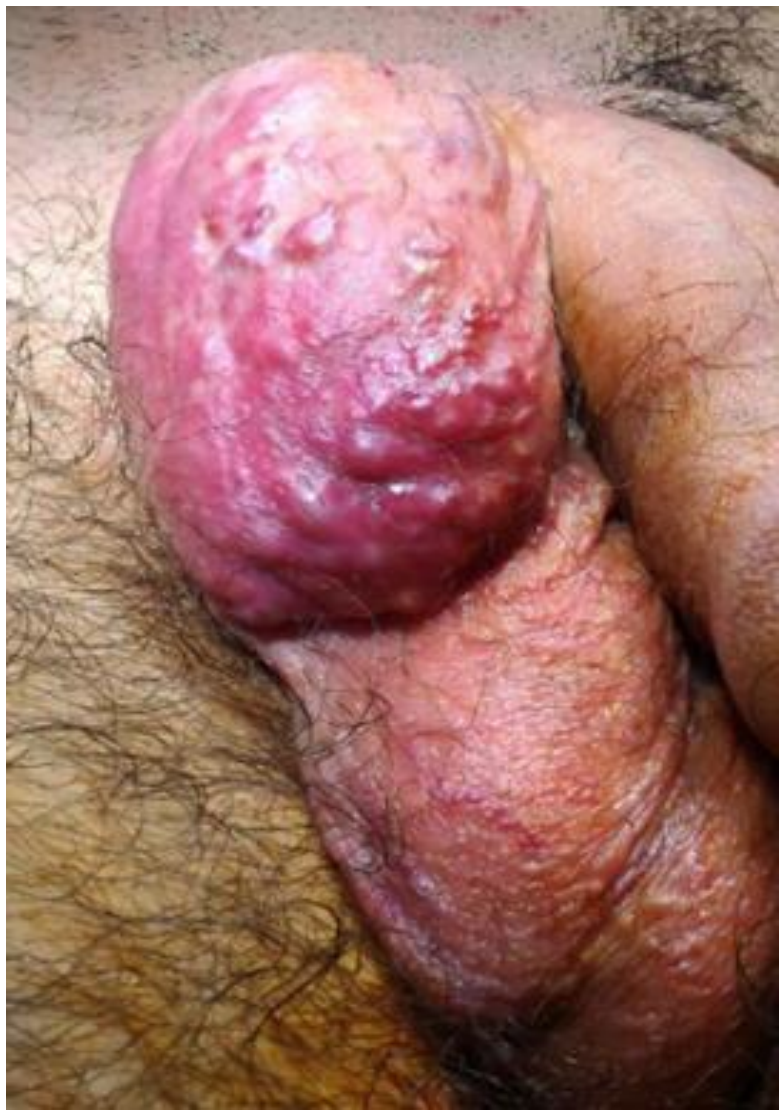

Resim 1: Klinik muayene sırasındaki gözlem

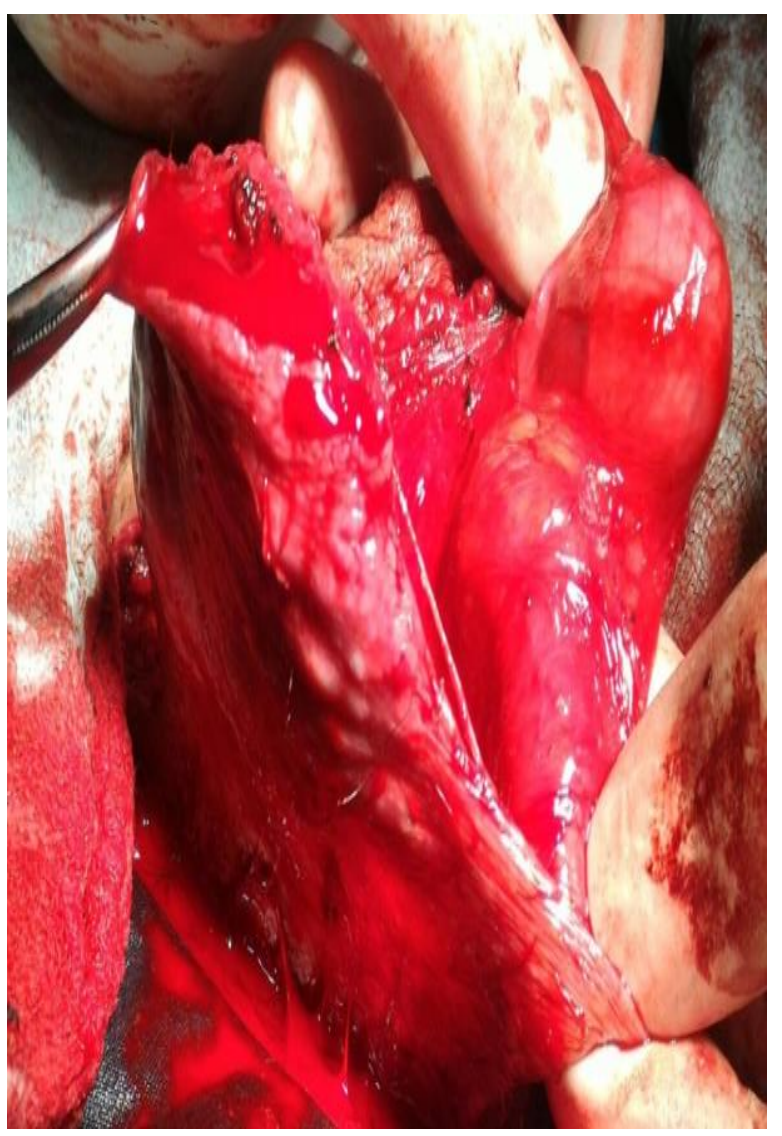

Resim 2: İntraoperatif eksize edilen testiküler kitle 
Doku spermatik kord üzerinden eksize edildi. Dokunun distal kısmı skrotum dokusuna çok yapışık olduğu için bu alan skrotum dokusu ile beraber eksize edildi. Hasta postoperatif 3. gün taburcu edildi.
Dokunun makroskopik görünümü hiperemik ve ödemliydi (Resim 2). Doku patolojik incelemeye alınd. Patoloji sonucu hemanjiom olarak tespit edildi.

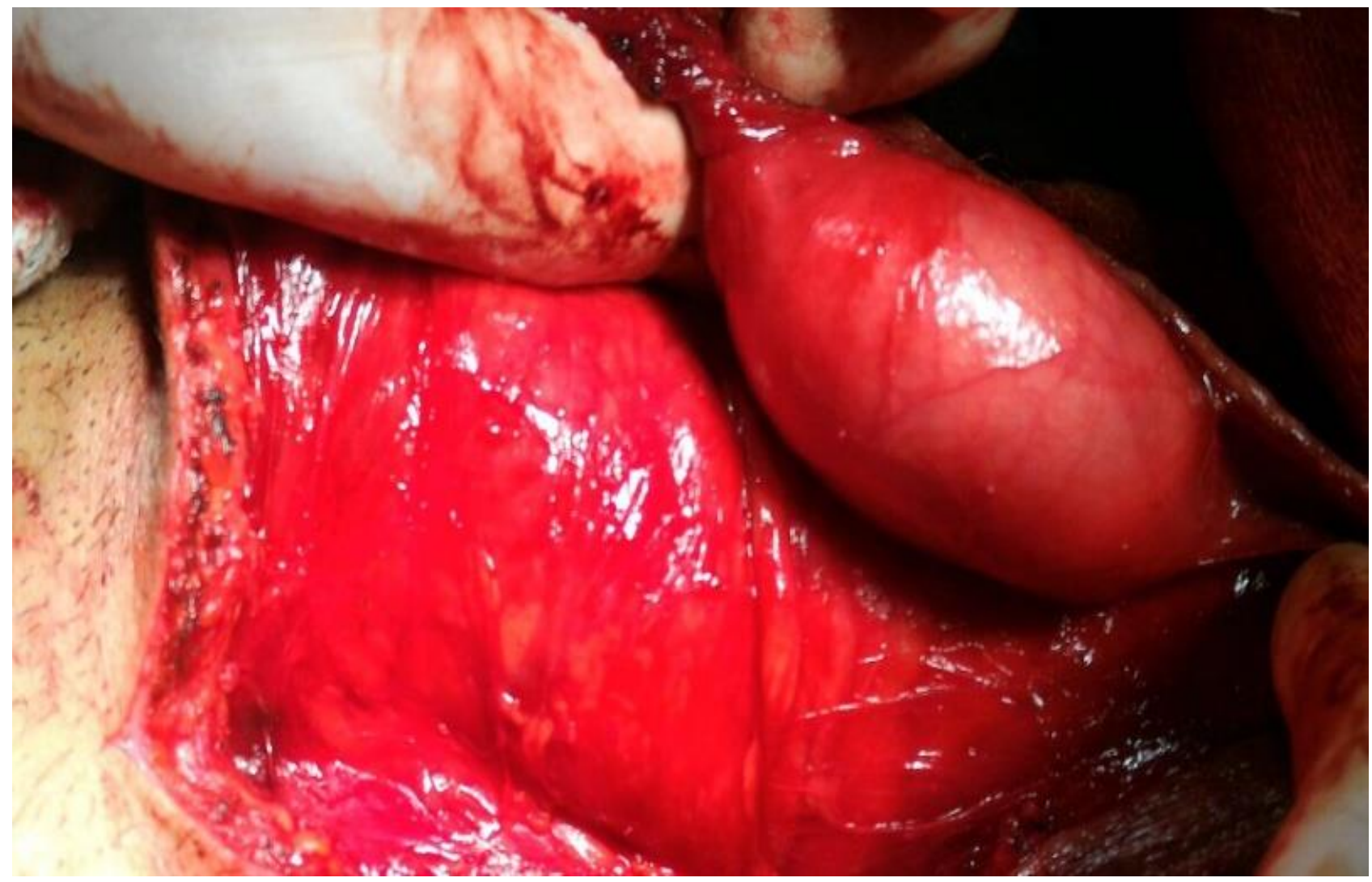

Resim 3: İntraoperatif doku eksizyonu sonrası testis dokusu

\section{TARTIŞMA}

Skrotumda; varikosel, hemanjiom, lenfanjiom, arteriovenöz malformasyonlar gibi çeşitli vasküler lezyonlar görülebilir. Bu lezyonlar içerisinde en sık görülen spermatik kord kaynaklı varikoseldir. Skrotal hemanjiom sık karşılaşılan klinik bir durum değildir. Skrotal hemanjiomlar genellikle çocukluk çağında görülmektedirler. Cilt altı skrotal ve perineal hemanjiomlar kasık fitığı ile karışabilirler. Bu yüzden skrotal hemanjiom tanısında görüntüleme yöntemleri önem taşımaktadır (8). Patoulias ve arkadaşları, 18 aylık erkek hastada görüntüleme yöntemleriyle skrotumun anterior yüzünde hemanjiom ile uyumlu 2.5 x $2.3 \mathrm{~cm}$ boyutlarında ve koresive olmuş lezyon tespit etmişlerdir. Takiben operasyon ile eksize edilen lezyonun patolojisi hemajiom olarak rapor edilmiştir (9). Büyük skrotal hemanjiomlar, skrotal 1s1 nedeniyle testise zarar verebilirler (10). Bu nedenle hemanjiomun eksizyonu gerekebilir. Görütüleme yöntemlerinde hemanjioma ait bazı karakteristik bulgular mevcuttur. Bilgisayarlı tomografi veya düz grafilerde görülen flebolitler hemanjiom tanisinı destekler (11-12). Doppler ultrasonografi ise hemanjiom içi kan akımını gösterdiği için hemanjiom tanısında yol göstericidir (13). Skrotal hemanjiom yetişkin dönemde sık rastlanılan klinik bir durum değildir. Ancak, Giuseppe ve arkadaşlarının yaptıkları bir çalışmada, metastatik renal hücreli kanser nedeniyle sunitinib tedavisi verilen 60 yaşındaki erkek hastada tekrarlayan skrotal hemanjiomlar tespit etmişlerdir (14). 
Skrotal hemanjiomlar nadir de olsa testis kaynaklı maligniteler ile karışabilir. Vavallo ve arkadaşları yaptıkları çalışmada, 52 yaşında erkek hastada sol epididime uzanan ve skrotal doppler ultrasonografide kanlanması olan lezyon tespit etmişlerdir. Ön tanı olarak epididim kaynaklı tümör düşündükleri lezyonun operasyon sirasinda spermatik korda ve testise yayılmadığını tespit etmişlerdir. Eksize edilen dokunun patoloji sonucu skrotal kaynaklı kapiller hemanjiom olarak tespit edilmiştir (15).

Skrotal hemanjiom nadir görülen klinik bir durumdur. Nadir olarak malignitelerle de karışabilen bu lezyonlar, çocuklarda daha sık görülmekle birlikte yetişkinlerde de görülebilmektedir. Ancak gelişen görüntüleme yöntemlerinin sayesinde hemanjiomların ayrıcı tanısı daha net olarak yapılabilmektedir.

\section{KAYNAKLAR}

1. Finn MC,Glowacki J,Mulliken JB. Congenital Vascular Lesions:clinical application of a new classification J Pediatr Surg. 1983;18:894-9.

2. Aydemir EH, Tüzün Y, Kotopyon A. Vasküler lezyonlar. Dermatoloji 1994, İstanbul: Nobel Kitabevi, 2.bask1. 1994:623-7.

3. Gampper TJ, Morgan RF. Vascular Anomalies: Hemangiomas Plast Reconstr Surg. 2002;110:57285.

4. Banton KL, D'Cunha J, Laudi N, Flynn C, Hammerschmidt D, Humar A, et al. Postoperative severe microangiopathic hemolytic anemia associated with agiant hepatic cavernous hemangioma. J Gastrointest Surg. 2005;9:679-85.

5. Pietrabissa A, Giulianotti P, Campatelli A, et al. Managementand follow-up of 78 giant haemangiomas of the liver. Br J Surg. 1996;83:9158.

6. Ergul O, Ceylan BG, Armagan A, Kapucuoglu N, Ceyhan AM, Perk H. A giant scrotal cavernous hemangioma extending to the penis and perineum: a case report. KaoJor Medical Science. 2008;139:177-86.
7. Şen Z, Özakpınar HR, Gökrem S, Özdemir OM, Ersoy A, Serel $S$ ve ark. Kutanöz vasküler lezyonlarda klinik yaklaşımlarımız Ankara Üniversitesi Tıp Fakültesi Mecmuası. 2002;55(3):193-204.

8. Ferrer FA, McKenna PH. Cavernous hemangioma of the scrotum: a rare benign genital tumor of childhood. J Urol. 1995;153(4):1262-4.

9. Patoulias I, Farmakis K, Kaselas C, Patoulias D. Ulcerated Scrotal Hemangioma in an 18-MonthOld Male Patient: A Case Report and Review of the Literature. Hindawi Publishing Corporation Case Reports in Urology Volume. 2016;2016:9236719

10. Gotoh M, Tsai S, Sugiyama T, Miyake K, Mitsuya H. Giant scrotal hemangioma with azospermia. Urology. 1983;22(6):637-9.

11. Djouhri H, Arrive L, Bouras T, Martin B, MonnierCholley L, Tubiana, JM. Diffuse cavernous hemangioma of the rectosigmoid colon: imaging findings. J Comput Assist Tomography. 1998;22(6):851-5.

12. Hervias D, Turrion JP, Herrera M, Navajas LJ, Pajares VR, Mancenido N, et al. Diffuse cavernous hemangioma of the rectum: an atypical cause of rectal bleeding. Rev Esp Enferm Dig. 2004;96(5):346-52.

13. Yeoman LJ, Shaw D. Computerized tomography appearances of pelvic hemangioma involving the large bowel in childhood. Pediatr Radiol. 1989;19(6):414-6.

14. Tonini G, Intagliata S, Cagli B, Segreto F, Perrone G, Onetti MA, et al. Recurrent Scrotal Hemangiomas During Treatment With Sunitinib Journal Of Clinical Oncology. 2010;28(35):737-8.

15. Vavallo A, Lafranceschina F, Lucarelli G, Bettocchi C, Ditonno P, Battaglia $\mathrm{M}$, et al. Capillary hemangioma of the scrotum mimicking an epididymal tumor: case report. Arch Ital Urol Androl. 2014;86(4):395-6. 